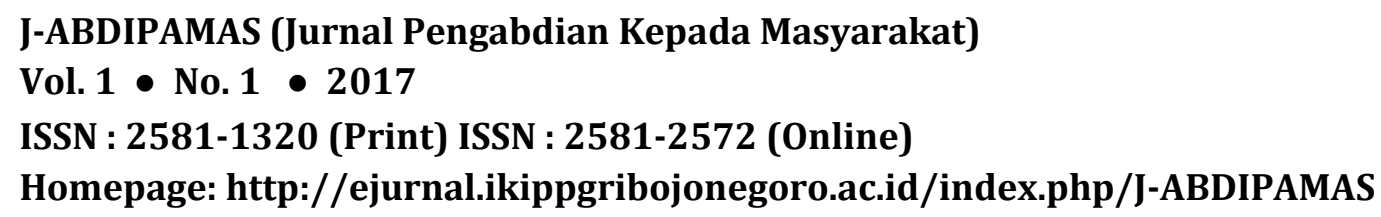

ISSN : 2581-1320 (Print) ISSN : 2581-2572 (Online)

Homepage: http://ejurnal.ikippgribojonegoro.ac.id/index.php/J-ABDIPAMAS

\title{
PELATIHAN PENGOLAHAN SAMPAH ORGANIK MENJADI KOMPOS DENGAN MEDIA KERANJANG TAKAKURA
}

\author{
M. Ali Ghufron ${ }^{1}$, Refi Ranto Rozak ${ }^{2,}$ Ayu Fitrianingsih ${ }^{3}$, Moh. Fuadul Matin ${ }^{4}$, \\ Ahmad Kholiqul Amin ${ }^{5}$ \\ ${ }^{1}$ IKIP PGRI Bojonegoro. Email: alghufron.87@gmail.com \\ ${ }^{2}$ IKIP PGRI Bojonegoro. Email: Refi.Ranto@ikippgribojonegoro.ac.id \\ ${ }^{3}$ IKIP PGRI Bojonegoro. Email: ayu.fitrianingsih@rocketmail.com \\ ${ }^{4}$ IKIP PGRI Bojonegoro. Email: fuadulmatin@gmail.com \\ ${ }^{5}$ IKIP PGRI Bojonegoro. Email: choliqamin@gmail.com
}

\begin{abstract}
ABSTRAK
Mitra dari kegiatan ini adalah SDN Pilang Kecamatan Kanor Kabupaten Bojonegoro. Mayoritas masyarakat desa Pilang bekerja sebagai petani. Dari hasil pertanian, mereka menghasilkan sampah organik yang melimpah. Selain itu, sampah organik juga dihasilkan dari dapur rumah tangga dan sekolah. Sisa-sisa olahan makanan dari dapur dan makanan dari sekolah juga turut menyumbang meningkatnya jumlah sampah organik. Sampah organik yang menumpuk tentunya akan berdampak yang kurang baik bagi kesehatan masyarakat. Penumpukan dapat dihindari dengan mengolah kembali sampah yang dihasilkan. Misalnya, sampah organik dapat dimanfaatkan kembali menjadi kompos. Tujuan dari kegiatan ini adalah memberikan pelatihan kepada mitra (siswa SDN Pilang) untuk membuat keranjang takakura (Takakura Home Method) sebagai media untuk mengolah sampah organik menjadi kompos. Kegiatan pelatihan ini dilaksanakan selama 1 (satu) hari dengan tiga tahapan utama, yaitu: persiapan, pelaksanaan, dan evaluasi. Akan tetapi hasil dan keberlanjutan kegiatan tersebut dipantau selama kurang lebih 2 (dua) minggu. Kelompok siswa diberikan pembimbingan oleh para mahasiswa berkaitan dengan keberlanjutan pembuatan kompos melalui media keranjang takakura tersebut. Hasil dari kegiatan menunjukkan bahwa mitra kegiatan ini mampu membuat keranjang takakura dan mengaplikasikannya untuk pengolahan sampah organik yang berada di sekitar lingkungan sekolah. Selain itu, kesadaran para siswa akan pemanfaatan sampah organik yang ada di lingkungan sekitar semakin meningkat.
\end{abstract}

Kata Kunci: kompos, keranjang Takakura, sampah organik

\section{ABSTRACT}

The Partner of this activity was SDN Pilang Kanor District Bojonegoro District. The majority of Pilang villagers work as farmers. From the agricultural production, they produce abundant organic waste. In addition, the organic waste is also produced from household kitchens and schools. Remnants of the processed food from the kitchen and food scraps from schools also contribute to the increasing amount of organic waste. Organic waste that accumulates will certainly have a negative impact on public health. Stacking of the organic waste can be avoided by reprocessing it; for example, organic waste can be reused into compost. The purpose of this activity was to provide training to the partners (SDN Pilang students) to make takakura basket (Takakura Home Method) as a medium to process organic waste into compost. This training was conducted for 1 (one) day with three main steps, i.e. preparation, implementation, and evaluation. However, the results and sustainability of the activities were monitored for approximately 2 (two) weeks. The group of students was given guidance by the university students related to the sustainability of composting through the takakura basket. The result of the activity shows that the partners of this activity are able to make takakura baskets and apply them to process of organic waste around the school environment. In addition, students' awareness of the utilization of organic waste in the surrounding environment is increasing.

Keywords: compost, organic waste, Takakura baskets 


\section{PENDAHULUAN}

Lingkungan merupakan sesuatu yang patut menjadi perhatian kita karena keberlangsungan hidup lingkungan adalah keberlangsungan hidup kita juga. Salah satu permasalahan lingkungan sekarang adalah mengenai sampah karena sampah dihasilkan oleh setiap individu terus-menerus tiap harinya, baik itu sampah organik maupun nonorganik. Sementara sampah baru dihasilkan setiap harinya, tempat untuk menampung sampah-sampah tersebut tidaklah bertambah sehingga jika dibiarkan akan mengakibatkan penumpukan sampah yang berujung pada timbulnya berbagai penyakit juga merusak keindahan lingkungan.

Pilang adalah sebuah desa yang berada di wilayah Kecamatan Kanor, Kabupaten Bojonegoro, Provinsi Jawa Timur, Indonesia. Desa Pilang terletak di tepi sungai Bengawan Solo, sehingga desa ini terkadang rawan banjir. Mayoritas masyarakat desa Pilang bekerja sebagai petani atau pekebun. Dari hasil pertanian atau perkebunan, mereka menghasilkan sampah organik yang melimpah. Selain itu, sampah orgamnik juga dihasilkan dari dapur rumah tangga dan sekolah. Sisa-sisa olahan makanan dari dapur dan sisa-sisa makanan dari sekolah juga turut menyumbang meningkatnya jumlah sampah organik. Sampah organik yang menumpuk tentunya akan berdampak yang kurang baik bagi kesehatan masyarakat. Penumpukan dapat dihindari dengan mengolah kembali sampah yang dihasilkan. Misalnya, sampah organik dapat dimanfaatkan kembali menjadi kompos. Salah satu cara mengolah sampah organik menjadi kompos adalah dengan menggunakan keranjang Takakura atau Takakura Home Method (Cintawati dan Handojo, 2014). Metode ini memang tergolong baru karena baru dipatenkan tahun 2006, tetapi Takakura Home Method merupakan salah satu cara yang praktis untuk dilakukan dan perawatannya pun tidak terlalu sulit. Namun, alternatif ini belum banyak dikenal sehingga "Pengenalan dan Pemberian Takakura" dirasa perlu untuk dilakukan.

Berdasarkan analisis situasi diatas, dapat dijabarkan bahwa permasalahan mitra adalah sebagai berikut: (1) melimpahnya sampah organik yang dihasilkan dari hasil pertanian atau perkebunan; (2) melimpahnya sampah organik sisa dapur rumah tangga dan sekolah; (3) kurangnya kesadaran warga dalam menyikapi masalah sampah organic; dan (4) warga belum mengetahui cara pemanfaatan dan pengolahan sampah organik dengan benar.

Berdasarkan uraian diatas, tim PKM mencoba memberikan solusi dengan pemberian pengetahuan kepada masyarakat desa Pilang (melalui siswa sekolah) tentang manfaat keranjang takakura untuk mengolah kembali sampah organik, serta perlakuan terhadap sampah organik sehingga cocok digunakan untuk metode ini. Para siswa tersebut juga memperagakan cara menggunakan keranjang takakura untuk menghasilkan kompos. Dengan demikian, manfaat yang diharapkan dari kegiatan PKM ini adalah agar masyarakat menjadi tahu dan mengerti tentang keranjang takakura, baik cara penggunaan maupun manfaatnya. Serta masyarakat bisa menggunakan keranjang takakura untuk menghasilkan kompos.

Keranjang Takakura adalah keranjang pembuat kompos (komposter) yang sangat ringkas dan praktis. Sesuai dengan namanya keranjang ini merupakan buah pemikiran 
Koji Takakura dari Jepang. Keranjang ini dirakit dari bahan-bahan sederhana di sekitar kita yang mampu mempercepat proses pembuatan kompos. Satu keranjang standar dengan starter $8 \mathrm{~kg}$ dipakai oleh keluarga dengan jumlah total anggota keluarga sebanyak 7 orang. Sampah rumah tangga yang diolah di keranjang ini maksimal 1,5 kg per hari. Penemuan Takakura bermula dari konsepsi sederhana dengan mencari solusi apa yang layak dan realistis dilakukan untuk memecahkan masalah timbunan sampah di masyarakat. Atas sponsor Kitakhyusu International Techno-cooperative Association (KITA) di Kota Kitakhyusu, Jepang, Koji Takakura melakukan penelitian di Surabaya bekerjasama dengan Pusat Pemberdayaan Komunitas Perkotaan (Pusdakota) Universitas Surabaya dan Pemerintah Kota Surabaya. Takakura menjadi peneliti kompos selama kerjasama tersebut sekaligus sebagai ahli pemberdayaan masyarakat (Pikiran Rakyat, 2008).

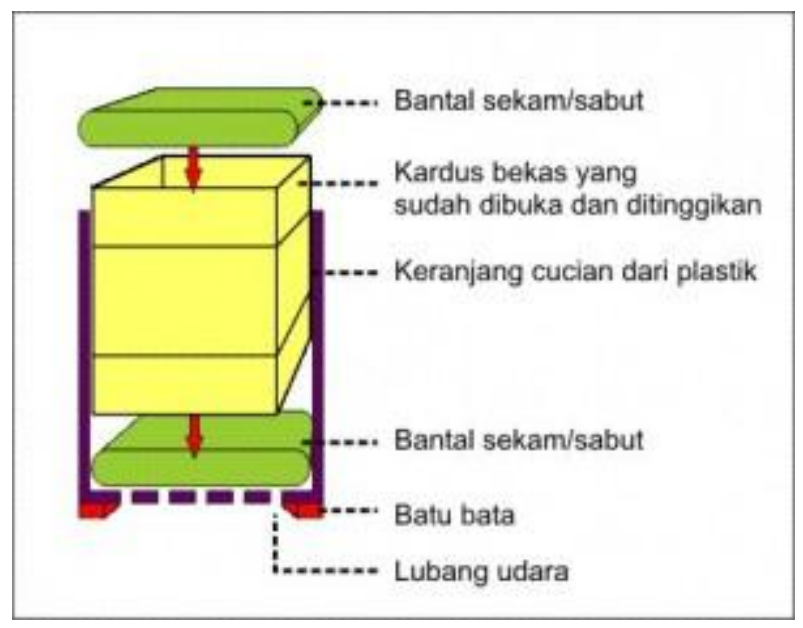

Gambar 1. Struktur Keranjang Takakura

Pada dasarnya keranjang Takakura dapat digunakan untuk mengkompos semua bahan organis (semua bahan yang berasal dari hewan dan tumbuhan). Dimana jumlah rata-ratanya sekitar $50 \%$ dari sampah rumah tangga. Keranjang Takakura dirancang untuk mengolah sampah sisa-sisa makanan, termasuk berbagai sisa bahan pada saat memasak (Sibu Municipal council, 2010). Keunggulan Keranjang Takakura diantaranya: (1) praktis dan murah untuk mengkompos di dalam ruangan dibanding kebanyakan metode pengkomposan lainnya yang harus dilakukan diluar ruangan; (2) ukuran keranjang relatif kecil tetapi kinerjanya tinggi : mampu mengkompos dengan cepat dan kecil kemungkinan terjadi bau. Walaupun ruang yang disisakan untuk mengkompos hanya $1 / 3$ wadah, tetapi wadah akan penuh paling cepat 2-3 bulan, untuk masukan 1-2 kg sampah per hari dengan jumlah anggota keluarga 5 - 7 orang; dan (3) alat dan bahannya mudah diperoleh, bahkan dapat dibuat sendiri media dan isinya (Pusdakota Ubaya, 2008).

\section{METODE PELAKSANAAN}

Metode pelaksanaan kegiatan ini terbagi menjadi tiga tahap, persiapan, pelaksanaan, dan evaluasi. Tahap persiapan dilakukan dengan presentasi definisi, cara kerja, manfaat, aplikasi, dan kontrol takakura. Tahap pelaksanaan dilakukan dengan 
siswa dan tim bersama-sama membuat keranjang takakura (peragaan pembuatan dan pengolahan sampah takakura) dan mencari sampah organik di lingkungan sekitar sekolah untuk diolah menjadi kompos. Tahap evaluasi dilakuakan dengan pengecekan dan tanya-jawab seputar teori dan praktek yang telah dilakukan bersama.

Agar dapat lebih memahami materi yang diberikan, diadakan lomba antarkelompok. Setiap kelompok ditugaskan menghasilkan kompos untuk lingkungan sekolah (dan rumah masing-masing jika hasil berlebih) dengan bahan baku sampah dari kelompok dan rumah siswa melalui penggunaan takakura. Kelompok yang memperoleh kompos terbanyak menjadi pemenang.

Adapun proses pembuatan keranjang Takakura menurut Rahmania (2012) adalah sebagai berikut:

1. Alat dan bahan:

a. Keranjang laundry dengan tutupnya 1 buah

b. Kardus bekas sekiranya cukup untuk dimasukkan ke dalam keranjang plastik

c. Gunting 1 buah

d. Isolasi secukupnya untuk merekatkan kardus pada keranjang

e. Kain jaring 1 meter.

f. Cetok / garu 1 buah

g. Jarum jahit dan benang untuk menjahit bantalan sekam

h. Sekam secukupnya masukkan dalam kain yang mudah menyerap air kemudian jahit menyerupai bantal, buat 2 bantal sekam.

i. Kompos siap pakai sebagai starter.

j. Sampah organik seperti sayuran, buah, dan nasi yang sudah ditiriskan dulu agar bebas air lalu dicacah kecil- kecil.

2. Proses pembuatan

a. Siapkan 1 buah keranjang plastik yang berlubang-lubang untuk sirkulasi udara (keranjang laundry) yang bertutup. Ukurannya hanya sekitar 50 liter, biasanya digunakan untuk keranjang wadah pakaian kotor sebelum dicuci

b. Ambil kardus dan potong dengan menggunakan gunting sesuai ukuran keranjang lalu tempelkam potongan kardus tadi di sekeliling bagian dalam keranjang. Tekan-tekan supaya masuk dan pas sehingga keranjang bisa ditutup. Kardus berfungsi sebagai perangkap starter kompos agar tidak tumpah, karena keranjang yang dipakai memiliki lubang yang relatif besar.

c. Gunting kain jaring untuk membuat dua kantong bantalan sekam sesuai ukuran alas dan bagian atas keranjang dengan cara menjahit bagian tepi jaring.

d. Setelah jaring berbentuk kantong, isi masing-masing kantong jaring dengan sekam secukupnya lalu jahit hingga menyerupai bantal. Jahit dengan gaya bebas semampunya. Bentuk akhir mirip bantal sekam, lebih padat lebih bagus. Buat dua buah.

e. Setelah bagian dalam keranjang terlapisi kardus, masukkan satu buah bantal sekam pada alas keranjang. Ini gunanya supaya cairan sampah dan kompos tidak merembes. Bantal sekam di bagian bawah keranjang berfungsi sebagai penampung air lindi dari sampah bila ada, sehingga bisa menyerap bau. Bantal 
sekam juga berfungsi sebagai alat kontrol udara di tempat pengomposan agar bakteri berkembang dengan baik.

f. Masukkan kompos siap pakai ke dalam keranjang kurang lebih setebal $5 \mathrm{~cm}$. Kompos berfungsi sebagai starter pada proses pengomposan karena di dalamnya terkandung mikroba-mikroba pengurai.

g. Masukkan sampah organik ke dalam keranjang, sampah yang hendak dikomposkan antara lain: Sisa makanan dari meja makan: nasi, sayur, kulit buahbuahan. Sisa sayuran mentah dapur: akar sayuran, batang sayuran yang tidak terpakai. Sebelum dimasukkan ke dalam keranjang, harus dipotong-potong kecilkecil sampai ukuran $2 \mathrm{~cm} \times 2 \mathrm{~cm}$. Sesekali tekan sampah dengan cetok hingga sampah berada di tengah- tengah kompos siap pakai.

h. Lapisi permukaan dengan salah satu kantong kain jaring berisi sekam yang telah disiapkan

i. Setelah dilapisi sekam, ambil kain jaring lagi untuk melapisi mulut keranjang guna menghindari masuknya hewan- hewan kecil / serangga.

j. Setelah mulut keranjang dilapisi kain jaring, tutup keranjang dengan tutup keranjang sampai tertutup rapat

k. Letakkan keranjang di tempat yang terhindar dari sinar matahari langsung.

l. Jika kompos terlihat kering perciki dengan air bersih sambil diaduk- aduk. Suhu idealnya 60 derajat celcius

m. Bila kompos telah penuh, ambil $1 / 3$ bagian dan matangkan di tempat yang tidak terkena sinar matahari langsung, sedangkan $2 / 3$ bagian dapat digunakan lagi sebagai starter untuk pengolahan berikutnya

n. Kompos matang, jika berwarna coklat kehitaman dan suhunya sama seperti suhu kamar (sekitar 20 sampai 25 derajat celcius)

3. Catatan :

a. Keranjang Takakura didesain untuk ukuran sampah rumah tangga sehari-hari dengan maksimum penghuni 7 orang. Bila jumlah anggota keluarga lebih dari itu, sebaiknya memakai Keranjang Takakura lebih dari satu buah.

b. Usahakan sampah organik masih segar dan dalam kondisi tercacah buah, sayuran ataupun nasi. Upayakan memasukkan sayuran yang belum basi. Bila sayuran telah basi, cuci dulu sayuran tersebut, tiriskan, dan bisa dimasukkan ke komposter Takakura.

c. Sebaiknya sampah organik segar yang diisi setiap hari, usahakan sampah ditekan dengan cetok sampai sampah timbunan baru tidak terlihat.

d. Ganti kardus yang menjadi lapisan dalam keranjang setelah 3-6 bulan atau ketika hancur.

e. Tidak ada belatung pada Keranjang Takakura meskipun setiap hari, para pemakai memasukkan sampah. Asal belatung adalah dari telur lalat. walaupun lalat telah bertelur pada makanan dan makanan tersebut dimasukkan ke Keranjang Takakura, telur lalat tersebut tidak akan menjadi belatung karena bahan-bahan yang ada di dalam keranjang takakura, misalnya, sekam, tidak memungkinkan perkembangbiakan belatung. 
f. Cuci kain penutup jika dirasa kotor.

g. Bila Keranjang penuh maka $1 / 3$ dari kompos itu dapat kita ambil dan dimatangkan di taman/kebun kita yang terlindungi dari sinar matahari selama kurang lebih 2 minggu untuk kemudian dapat digunakan sebagai pupuk kompos.

h. Untuk mengetahui kalau proses pengomposan terjadi dengan baik, Cara paling gampang adalah dengan meletakkan telapak tangan kita kurang lebih $2 \mathrm{~cm}$ di atas kompos. Bila terasa hangat, bisa dipastikan proses pengomposan berjalan dengan baik. Bakteri yang mendukung proses pengomposan sedang bekerja. Bila telapak tangan tidak terasa hangat, bakteri tidak bekerja maksimal. Bisa jadi kompos starter tersebut terlalu kering hingga memerlukan air. Percikkan air pada kompos tersebut. Pelan-pelan, suhu dari starter tersebut akan meningkat dengan bekerjanya mikroorganisme yang mengubah sampah menjadi kompos.

Karena proses pengomposan ini 'aerob' atau membutuhkan oksigen, isi keranjang sebaiknya diaduk-aduk dengan sekop / cetok setiap hari.

i. Umumnya, keranjang Takakura penuh antara 2-4 bulan, tergantung jumlah sampah yang dimasukkan. Bila sudah penuh, ambil sepertiga bagian paling atas. Kompos yang diambil tadi didiamkan 14 hari, barulah bisa dipakai. Sedangkan yang tetap tinggal di keranjang, bisa dipakai sebagai starter untuk pengomposan kembali

j. Hindarkan dari terik matahari, agar keranjang tidak cepat rusak dan kompos tidak cepat kering dan hindarkan dari hujan (taruh di tempat teduh) keranjang Takakura dirancang sedemikian rupa sehingga dalam keadaan normal, keranjang tidak menghasilkan bau.

4. Panduan Penggunaan Keranjang Takakura

a. Buka keranjang Takakura, kain penutup dan bantalan sekam

b. Gali media pengkomposan dengan sekop kecil tepat di tengahnya sehingga terbentuk lubang. Sesuaikan ukuran galian dengan jumlah sampah yang akan dimasukkan.

c. Kemudian masukkan sampah organis yang akan anda kompos.

d. Timbun sampah tadi dengan menggunakan media yang ada di tepian lubang sehingga sampah tertutupi.

e. Tutup kembali dengan bantal sekam.

f. Tutup kembali keranjang Takakura dengan kain penutup dan penutup keranjang Di hari berikutnya ketika kita akan memasukkan sampah, terlebih dahulu perlu melakukan pengadukan secukupnya, supaya sampah yang dimasukkan sehari sebelumnya tercampur merata dengan media pengkomposan. Setelah itu lakukanlah langkah no. 2 hingga no. 6 seperti di atas.

5. Panen Kompos

Bila keranjang sudah penuh, maka $1 / 3$ bagian dari isi keranjang sudah dapat diambil untuk dijadikan kompos.

a. Keluarkan media pengomposan dari keranjang. Kemudian pisahkan media yang warnanya lebih gelap dan halus (sudah menjadi kompos) 
b. Untuk mengambil yang paling lembut, bisa mengayaknya dengan menggunakan tutup keranjang. Jumlah yang dikeluarkan sebanyak $1 / 3$ isi keranjang.

c. Kemudian masukkan kembali $2 / 3$ bagian sisa pengayakan termasuk sampahsampah yang belum terurai ke dalam keranjang untuk menjadi media pengomposan selanjutnya. Tempatkan sampah organis yang belum terurai di bawah media pengomposan.

d. Kompos yang dipanen kita matangkan terlebih dahulu selama setidaknya satu minggu. Setelah itu kompos siap digunakan.

6. Mengatasi Masalah Takakura

Masalah takakura yang paling sering ditemui yaitu:

a. Bau: Campurkan sejumlah sekam ke dalam kompos(semakin bau semakin banyak). Aduk hingga merata, kemudia tutup kembali keranjang takakura

b. Pengomposan terhenti dan menjadi dingin: Hal ini biasa terjadi jika pengurai berhenti bekerja. Untuk mengatasinya bisa dengan menambahkan segenggam bekatul dan segelas air gula. Aduk merata.

c. Terlalu basah: Tambahkan sejumlah sekam, kemudian aduk-aduk bersama sampah lainnya Terlalu kering: Tambahkan air dan aduk.

d. Tinggi kompos kurang dari setengah bagian: campurkan sekam hingga tingginya mendekati 2/3 bagian. Tambahkan beberapa genggam bekatul dan aduk merata.

\section{HASIL DAN PEMBAHASAN}

Hasil dari kegiatan Pengabdian kepada Masyarakat (PKM) ini menunjukkan bahwa kelompok mitra (dalam hal ini adalah siswa SDN Pilang Kecamatan Kanor Kabupaten Bojonegoro) mampu membuat keranjang takakura dan mengaplikasikannya untuk pengolahan sampah ornagik menjadi kompos. Adapun hasil dari tahapan pembuatan keranjang takakura yang dilakukan oleh siswa SDN Pilang secara garis besar terbagi menjadi tiga tahap sebagai berikut:

\section{Tahap Persiapan}

Dalam tahap ini, para siswa diberi pembekalan materi atau pemahaman mengenai sampah organik dan dan cara pembuatan keranjang takakura oleh tim PKM. Para siswa diberikan pemahaman yang menyeluruh tentang sampah, dampak sampah terhadap lingkungan, sampah organik dan cara pemanfaatannya, serta cara membuat media untuk pengolahan sampah organik menjadi kompos, yakni keranjang takakura. Para siswa terlihat sangat antusias dan sesekali diantara mereka bertanya dan menjawab pertanyaan yang diberikan oleh tim guna mengecek kepahaman mereka. 


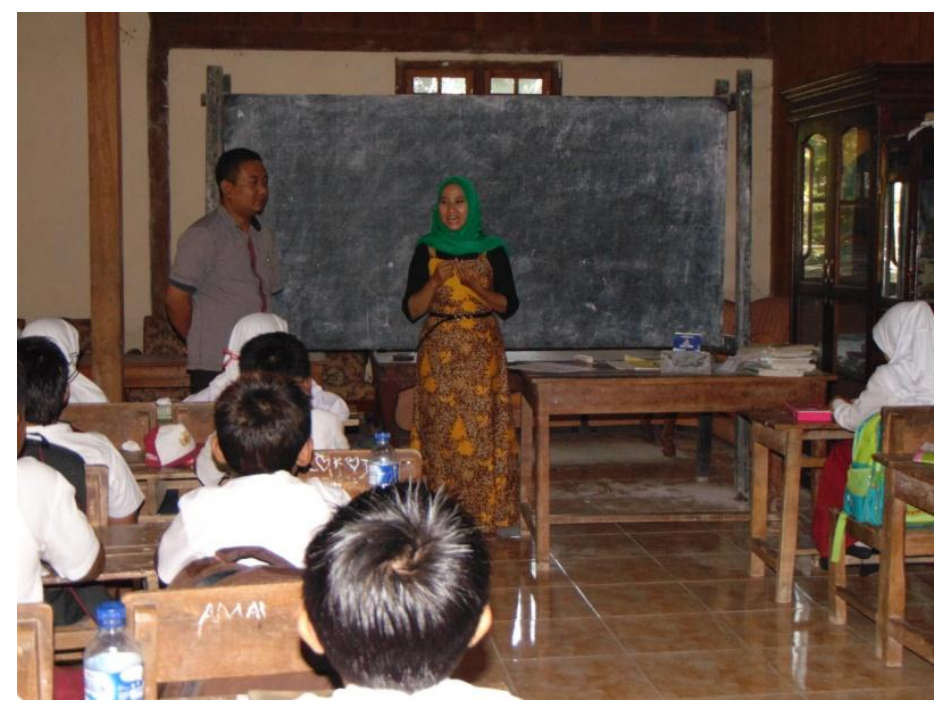

Gambar 2. Tim PKM memberikan Pengetahuan tentang sampah organik dan keranjang Takakura

\section{Tahap Pelaksanaan}

Dalam tahap ini, para siswa dan tim PKM bersama-sama membuat keranjang takakura dengan bahan dan media yang telah disiapkan sebelumnya oleh tim. Kelompok siswa terbagi menjadi 2 (dua). Sebelum memulai peragaan, tim menjelaskan bahanbahan dan media yang akan digunakan untuk membuat keranjang takakura. Setelah itu, tim bersama siswa mulai menyusun bahan-bahan dan media menjadi keranjang takakura. Setalah masing-masing tim selesai membuat keranjang takakura, para siswa mencari sampah organik yang ada di lingkungan sekolah. Mereka mencari sampah organik dengan berbekal pengetahuan materi tentang sampah organik yang telah diberikan oleh tim pada saat tahap persiapan. Setelah sampah organik terkumpul, para siswa memasukkan sampah tersebut kedalam keranjang takakura.

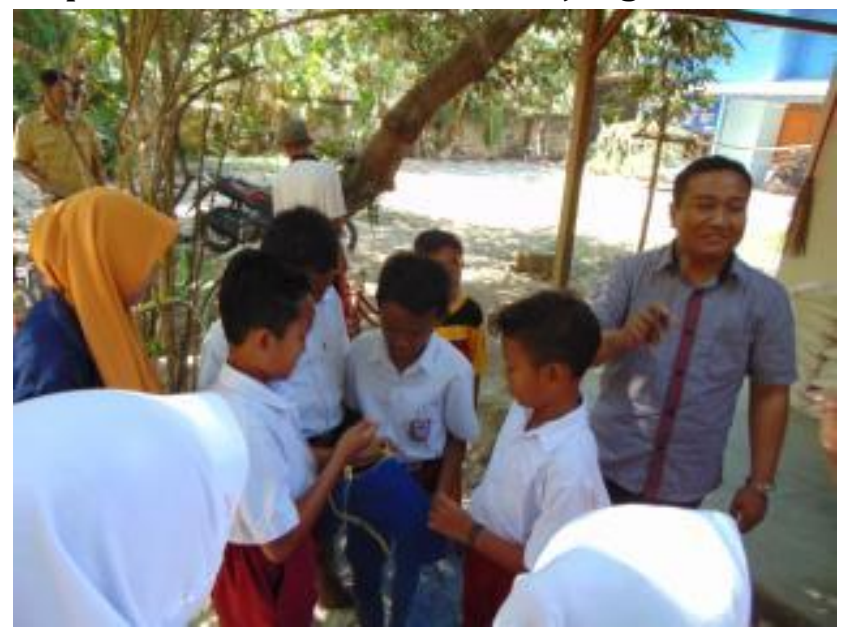

Gambar 3. Tim dan para siswa menjahit kain kasa (jaring) untuk membuat bantal sekam 


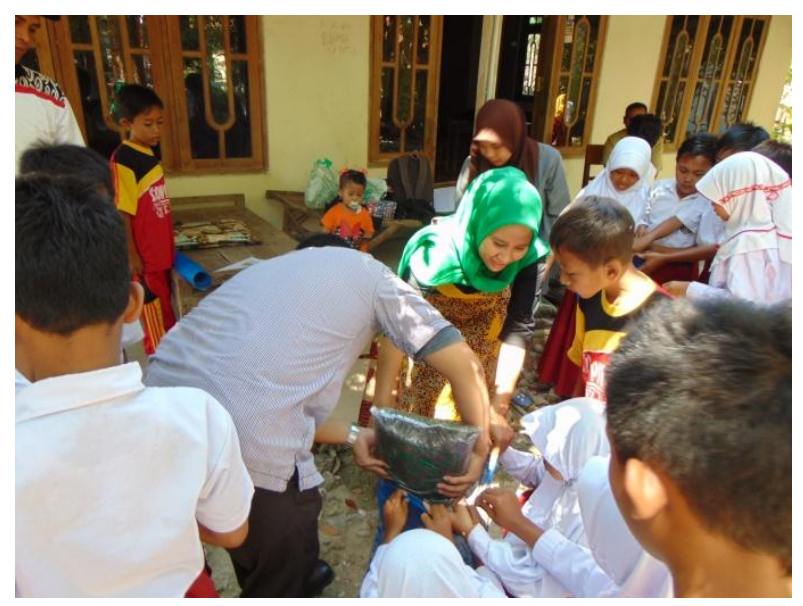

Gambar 4. Tim dan para siswa mengisi kain jaring dengan sekam

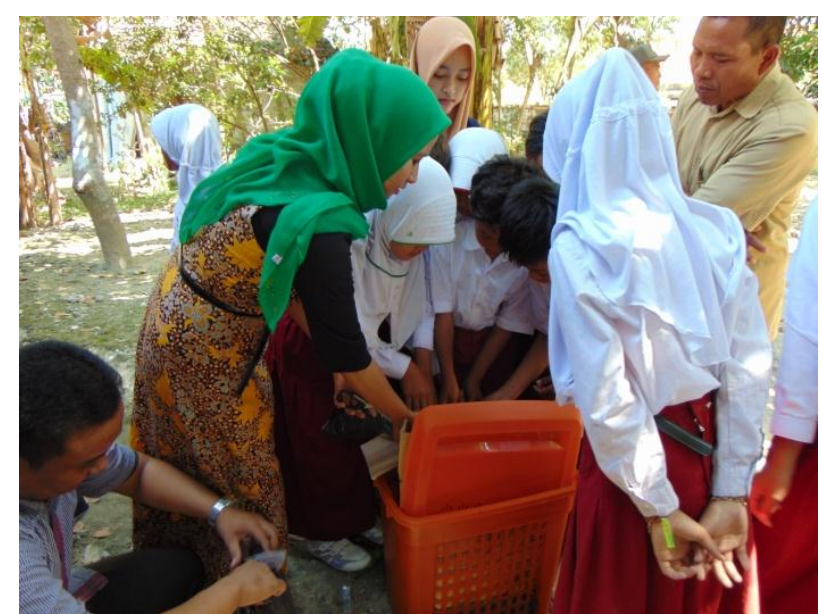

Gambar 5. Keranjang takakura hampir selesai (siap diisi dengan dengan sampah organik)

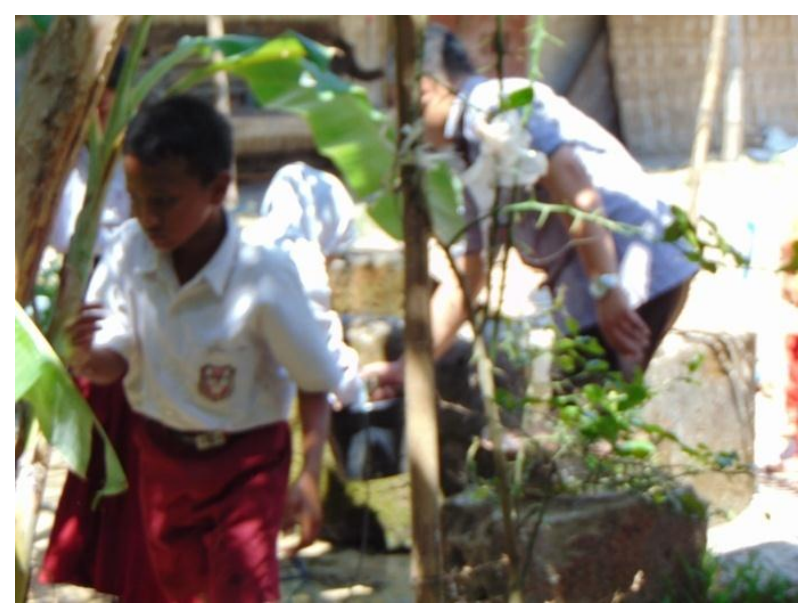

Gambar 6. Sebagian siswa mencari sampah organik di lingkungan sekitar 


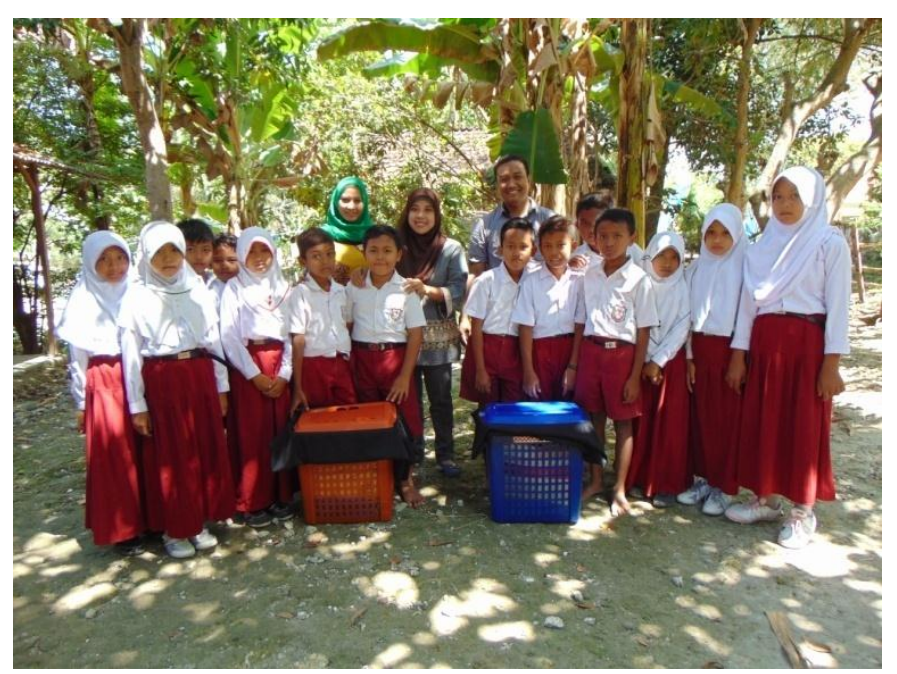

Gambar 7. Keranjang takakura setelah diisi sampah organik dan siap memprosesnya menjadi kompos

\section{Tahap Evaluasi}

Dalam tahap ini, tim dan para siswa bersama-sama melakukan kegiatan diskusi dan tanya-jawab seputar teori yang telah diajarkan pada tahap persiapan dan kegiatan peragaan yang telah dilakukan pada tahap pelaksanaan. Tim melontarkan beberapa pertanyaan terkait materi kepada para siswa. Dalam proses diskusi dan tanya jawab, tim menyediakan reward kepada siswa yang berani bertanya dan atau yang bisa menjawab pertanyaan yang diberikan oleh tim. Hal ini dilakukan untuk memotivasi para siswa agar berani memberikan pendapat dan menjawab pertanyaan.

Dalam tahap ini, tim juga menggali pendapat siswa mengenai kegiatan yang telah dilakukan dan tanggapan mereka mengenai pengolahan sampah organik yang ada di lingkungan sekolah mereka. Dari hasil diskusi dapat disimpulkan bahwa kesadaran para siswa akan pengolahan sampah organik yang ada di lingkungan sekitar mereka menjadi kompos semakin meningkat.

\section{SIMPULAN}

Dari kegiatan yang telah dilakukan oleh tim PKM dari IKIP PGRI Bojonegoro dengan sasaran mitra SDN Pilang Kecatamatan Kanor Kabupaten Bojonegoro, dapat disimpulkan bahwa masyarakat (khususnya para siswa SD) tidak sepenuhnya acuh terhadap permasalahan sampah organik yang ada di lingkungan sekitar mereka. Mereka hanya butuh pemahaman dan dan pembimbingan agar mampu mengubah sesuatu yang tidak bermanfaat menjadi bermanfaat. Mengubah sampah organik menjadi kompos adalah salahsatunya. Kegiatan ini membuktikan bahwa ketika masyarakan diberikan pemahaman dan pembimbingan mereka akan dengan senang hati melakukan hal tersebut sehingga mampu mengubah sesuatu yang negatif menjadi positif. Siswa SDN Pilang secara khusus telah membuktikan bahwa mereka mampu membuat media yang bisa mereka manfaatkan untuk mengolah sampah organik menjadi pupuk kompos, yaitu media keranjang takakura. Selain itu, dengan keterampilan baru yang mereka miliki, kesadaran akan pengolahan sampah organik juga semakin meningkat. 


\section{DAFTAR RUJUKAN}

Cintawati, Nyi Raden; Handojo, Oemar;. (2014). Desain Alat Pengompos sampah Rumah Tangga: Pengembangan Lanjut dari Keranjang Takakura. Retrieved September 29, 2017, from Jurnal Tingkat Sarjana Seni Rupa dan Desain, No. 1: https://www.google.co.id/url?sa=t\&rct=j\&q=\&esrc=s\&source=web\&cd=22\&cad $=$ rja\&uact=8\&ved=0ahUKEwjknpDM6IrXAhUDsI8KHZ33CVA4FBAWCDMwAQ\&u rl=http $\% 3 \mathrm{~A} \% 2 \mathrm{~F} \% 2 \mathrm{Fjurnal}-$ s1.fsrd.itb.ac.id\%2Findex.php\%2Fproduct\%2Farticle\%2Fdownload\%2F432\%2F 374\&usg=AOvVaw00lintcTsw3VuORanw

Municipal, S. C. (2010). Takakura Home Method (THM) Composting. Retrieved September 29, 2017, from Sibu Municipal Council: http://sdi.com.my/docs/Takakura_resized.pdf

Pikiran Rakyat. (2008). Koji Takakura (1959-Sekarang) Penemu Keranjang Pengompos Sampah. Retrieved September 29, 2017, from Pikiran Rakyat: https://klipingut.wordpress.com/2009/11/25/koji-takakura-1959-sekarangpenemu-keranjang-pengompos-sampah/

Pusdakota Ubaya. (2008). Keranjang Takakura. Retrieved September 29, 2017, from Pusdakota Ubaya: http://keranjangtakakura.blogspot.com/2008/09/membuatkeranjang-takakura.html

Rahmania, R. (2012). Go Green dengan Keranjang Takakura. Retrieved September 29, 2017, from Klipingut.wordpress.com.

Rahmania, R. (2012). Go Green dengan Keranjang Takakura. Retrieved September 29, 2017, from wordpress.com: http://ririspunyamimpi.blogspot.com/2012_01_21_archive.html 